NBER WORKING PAPER SERIES

A PUBLIC FINANCE APPROACH TO ASSESSING POVERTY ALLEVIATION

Shlomo Yitzhaki

Working Paper 8062

http://www.nber.org/papers/w8062

\author{
NATIONAL BUREAU OF ECONOMIC RESEARCH \\ 1050 Massachusetts Avenue \\ Cambridge, MA 02138 \\ January 2001
}

The paper is based on a report prepared for OED, The World Bank. I am grateful to Harold Alderman, Lionel Demery, Alison Evans, Margaret Grosh, Ravi Kanbur, Reuben Lamdany, Martin Ravallion, Lyn Squire and Michael Walton for sharing their views with me. I would like to thank Shanta Devarajan, Robert Lerman, Joel Slemrod and Vito Tanzi for their comments. Needless to say that I am the only one who is responsible for the content of the paper. The views expressed herein are those of the author and not necessarily those of the National Bureau of Economic Research.

(C) 2001 by Shlomo Yitzhaki. All rights reserved. Short sections of text, not to exceed two paragraphs, may be quoted without explicit permission provided that full credit, including (C) notice, is given to the source. 
A Public Finance Approach to Assessing Poverty Alleviation

Shlomo Yitzhaki

NBER Working Paper No. 8062

January 2001

JEL No. H2, I3

ABSTRACT

This paper points out the similarities and differences between cost-benefit analysis and tax reform. By restricting the analysis to the margin it is shown that both areas can be handled by the same method. In both areas, there is a need to define social distributional weights and to evaluate the Marginal Efficiency of Public Funds (MECF). It is suggested that the social distributional weights be derived from popular inequality indices. Such derivation, enables the decomposition of the impact of the project (tax reform) on growth and redistribution so that one can evaluate the trade-off between the two.

\author{
Shlomo Yitzhaki \\ Department of Economics \\ Hebrew University \\ Jerusalem, 91905 \\ Israel \\ and NBER \\ msruhama@mscc.huji.ac.il
}

Fax: 972-2-5816071 


\section{A Public Finance Approach to Assessing Poverty Alleviation}

The systematic listing of and comparison between the costs and benefits associated with any policy measure is a fundamental tool of the decision making process developed by economists. The theory and practical evaluation of costs and benefits under different circumstances, such as market distortions and imperfections, externalities and risk, has been refined in several handbooks and hundreds of papers. ${ }^{2}$

Cost-benefit analysis involves efficiency considerations and distributional issues. Both issues require value judgement. However, whereas efficiency considerations require the minimal value judgement embodied in the Pareto criterion (which approves any cost-less improvement in the economic welfare of any individual), distributional issues require the evaluation of the social value of benefits and costs accruing to different individuals. When it comes to distributional issues, the handbook recommendation is to apply distributional weights, but it is not clear from where to draw these distributional weights, and it is hard to defend the use of arbitrary weights. Moreover, some experiments using distributional weights led Harberger to conclude that "the implication for policy of a thorough and consistent use of distributional weights turn out to be quite disturbing" (Harberger, 1978, p. S111). ${ }^{3}$

Until quite recently, this weakness of cost-benefit analysis could be dismissed as not crucial because the primary interest of The World Bank and other major users of costbenefit analysis was in lending for and approving physical projects which are primarily intended to promote growth. In this case, one can ignore distributional considerations due to several possible approaches: (a) one does not care about distributional issues, (b) distributional issues are dealt with by other instruments (c) it is assumed that the status quo represents the optimal income distribution. ${ }^{4}$ However, about a decade ago the

\footnotetext{
${ }^{2}$ See Jenkins (1997) for an illuminating review of the connection between project analysis and evaluation and The World Bank. Among the handbooks written on the subject it is worth mentioning Little and Mirrlees $(1969,1974)$, Pearce and Nash (1981) and Squire and van der Tak (1975). Dreze and Stern (1987) offer a review of the main theoretical aspects of the topic.

${ }^{3}$ See Squire (1980) for a counter argument.

${ }^{4}$ See Pearce and Nash (1981) who argue that "a decision to adopt no weighting scheme is itself equivalent to adopting a particular value judgement, namely, that the existing distribution of income is optimal." (p. 34). See also Copp (1987) who presents an excellent discussion of the rationale of cost-benefit analysis.
} 
emphasis has changed from growth and physical projects to poverty reduction and social lending. This change in emphasis has made the above weakness a major obstacle to implementing cost-benefit analysis. So much so, that cost-benefit analysis appears to have been virtually abandoned in favor poverty measurement and general policy advice. ${ }^{5}$ This is regrettable because I believe that cost-benefit analysis is an important tool which could contribute to the analysis of poverty reduction programs.

The inconvenience in choosing distributional weights is discussed in depth by Devarajan, Squire and Suthiwart-Narueput (1995) and will not be repeated here. But it should be emphasized that the need for a value judgement is not restricted to cost-benefit analysis. It is almost always required for any analysis of distributional issues. In fact, behind every inequality and poverty measure there is a detailed quantitative set of assumptions about distributional weights. The main difference seems to be that unlike cost-benefit analysis, where one has to choose and defend his particular distributional weights, the use of distributional weights in the form of a poverty or inequality measures is easier because one simply has to join the bandwagon of those who are using that measure. Hence, instead of having to defend one's subjective distributional weights, one only has to justify the use of the poverty or inequality measure. In this sense, the alternatives to costbenefit analysis do not obviate the need to choose distributional weights; they simply make it easier. A methodology that introduces indirectly distributional weights into cost-benefit analysis can, therefore, free the analyst from this inconvenient choice.

The aim of this paper is to illustrate the derivation and application of distributional weights through the use of an inequality measure. This method enables the indirect choice of distributional weights through the use of an inequality measure, and therefore enables the use of cost-benefit analysis without forcing the analyst to directly choose and defend the distributional weighting scheme. In my opinion, the method can be applied to any inequality or poverty measure. However, since I don't know of a general method of doing that, the illustration will be restricted to the use of the Gini coefficient and Atkinson index of inequality.

\footnotetext{
${ }^{5}$ As in any generalization, one can point out several exceptions. Among them see Ravallion and Datt (1995),
} 
The illustration is done by proposing an answer to the following specific question: what is the quantitative impact on the mean and the distribution of economic well-being in society of a program (or project) that is fully or partly financed by public funds? The discussion is limited to the theoretical aspects of the problem.

The ability to answer the above question is the cornerstone of any evaluation program, since it enables one to rank projects (and programs) according to their contribution to growth (or efficiency) and redistribution.

The discussion in this paper relies heavily on some new approaches in the field of tax reform, which can quite easily be transformed into cost-benefit analysis of projects and reforms. Hence the title of the paper.

The structure of the paper is as follows: Section 1 provides the basic ingredient of the evaluation of a tax tax reform, restricting the analysis to one period; Section 2 applies the analysis to an investment project by extending the approach to a two-period model. Section 3 concludes.

\section{THE BASIC FRAMEWORK OF THE MODEL (ONE PERIOD)}

\subsection{The Basic Framework}

Consider an economy with $\mathrm{H}$ households. Each household has a well-behaved utility function $\mathrm{u}^{\mathrm{h}}(\mathrm{)}$, unknown to the investigator, and an observed budget allocation, $y^{h}=\sum_{i} q_{i} x_{i}^{h}$, where $q_{i}$ is the price of the $i$-th commodity, $x_{i}^{h}$ is the quantity consumed by household h and $y^{h}$ is after-tax income. Assume that the vector of producers' prices, $p_{i}$, is given, and that $t_{i}=q_{i}-p_{i}$ are the tax rates. The above assumptions mean that the production side of the economy is ignored. It is also assumed that taxes are borne by the consumers.

Assume that the government can be represented as trying to maximize a social welfare function defined over the indirect utility functions of individuals. Hence, individuals are

and several other publications listed in Squire (1995). 
assumed to maximize their utility functions subject to the given prices, and society as a whole seeks to maximize those utilities according to the weights assigned by the social welfare function. Assume, too, that at this stage we are dealing with a one-period model, i.e., investment that takes time to mature is not considered. To simplify the presentation it is also assumed that there are no externalities, no public goods, and that our analysis is restricted to analysis at the margin. The question is, therefore: if one tax (or subsidy) is increased and another tax (or subsidy) is decreased, while keeping tax revenue intact, what will be the impact on the social welfare function?

This framework imposes very few mild assumptions on the production side of the economy. Specifically, no assumptions are made as to whether the economy is efficient or not, nor whether markets are complete. Also, no structure is assumed on the markets. The only assumptions made are that consumers are price takers and that the incidence of a change in the price of a good is borne solely by the consumers.

The assumptions needed for the analysis can be classified into crucial and non-crucial ones. Crucial assumptions can not be changed without seriously affecting the implications of the model, such as: (a) restricting the analysis to the margin, (b) that prices are given to individuals, and (c) that the social welfare function is based on individuals' preferences. Non-crucial assumptions can be removed with some modest modification of the model, such as: (a) non-existence of public goods, (b) externalities, and (c) a one period model. The assumption of one period model will be removed in the next section.

The most crucial assumption here is the restriction of the analysis to analysis at the margin. This assumption substantially reduces the amount of counterfactual information needed for the analysis of the impact of a program. For example, assuming that a project is not on the margin may raise the following hypothetical question: suppose the project will make future beneficiaries rich (say, if it raises the schooling level of poor students); should these beneficiaries be treated as rich (because they will be rich as a result of the project) or poor (as they are in the present)? The question is whether to treat a potentially rich person as a rich person or as a poor one. In addition to this problem, the evaluation of nonmarginal projects requires estimating counterfactual outcomes. The assumption that we are operating at the margin is reasonable whenever the nature of the project is not likely to 
have a drastic impact on the status of the beneficiaries, or if the number of beneficiaries that are drastically affected is relatively small. A change of less than 20 percent in income can be safely approximated by a marginal approach. In practice, marginal analysis is relevant whenever changes in the economy are such that first-order approximations are relevant. ${ }^{6}$

The formal problem faced by the government is:

$$
\begin{aligned}
& \operatorname{Max}_{t_{1}, t_{2}, \ldots, t_{n}} W\left[V^{1}\left(q_{1}, \ldots, q_{n}\right), \ldots, V^{H}\left(q_{1}, \ldots, q_{n}\right)\right] \\
& \text { s.t. } \quad R=\sum_{j=1}^{J} t_{j} X_{j},
\end{aligned}
$$

where $W$ is the social welfare function, $V^{h}$ is the indirect utility function of individual $h, q_{j}$ is the consumer's price of commodity $j, t_{j}$ is the tax rate on commodity $j$ and $X_{j}=\sum_{h} x_{i}^{h}$ is the consumption of unit $j$. Bear in mind that the government is assumed to be interested in maximizing the social welfare function subject to a revenue constraint, $R$. However, no assumption is made as to whether or not the government is successful in achieving this goal. Also, there is no assumption concerning the structure of the economy.

The next step is to modify the above problem to deal with tax reform. In a tax reform the government is restricted to changing prices in the economy while when a public project is considered the government can change both prices and quantities. The adjustment to include project evaluation is postponed to the next section.

Assume that the economy is in equilibrium, i.e., there is a given set of prices and incomes, a given set of tax rates, and given individuals' consumption baskets. The economy need not necessarily be at an optimum. However, it is assumed that the budget constraint is binding.

Assume that in order to increase social welfare the government considers raising one tax (denoted by $t_{t}$ ) by a small amount and reducing another tax $\left(t_{s}\right)$, while keeping the budget constraint intact. We wish to investigate the implications of such a reform on the

\footnotetext{
${ }^{6}$ Kleiman (1972) offers an example showing the weakness of a marginal analysis. Subject to general equilibrium considerations he shows that an increase in the tax on the rich may deteriorate income distribution.
} 
social welfare function. To answer this question we must find the derivative of the social welfare function with respect to the proposed change in prices. Since the government's budget constraint is given, the changes in the tax rates, $t_{s}$ and $t_{t}$, are connected through the budget constraint. That is:

$$
\frac{\partial R}{\partial t_{t}} d t_{t}+\frac{\partial R}{\partial t_{S}} d t_{S}=M R_{t} d t_{t}+M R_{S} d t_{S}=0
$$

where $M R_{t}$ is the marginal change in tax revenue due to the change in tax $t$. Assuming that the economy is on the increasing side of the Laffer curve means that both $M R_{t}$ and $M R_{s}$ are positive, and since it is assumed that $d t_{t}>0$, the revenue constraint requires that $d t_{s}$ be negative and its magnitude be determined by equation (2). Equation (2) means that the change in the tax revenue caused by the increase in the first rate and the change in the tax revenue caused by the decrease in the second rate should add up to zero. Hence, although the reform involves two changes in taxes, there is actually only one free parameter.

To evaluate the effect of the reform on the social welfare function let us start with the impact of a change in the price of commodity $i$ on the individual $h$. According to Roy's identity, the following relationship holds:

$$
\frac{\partial V^{h}}{\partial t_{i}}=-V_{y}^{h} x_{i}^{h},
$$

where $V_{y}^{h}$ is the marginal utility of income of individual $h$ and $x_{i}^{h}$ is the quantity of the commodity. ${ }^{7}$ Equation (3) means that at the margin, and for an individual who maximizes his utility, the effect on the individual of a change in the price of a commodity is determined by the quantity consumed and by the marginal utility of income. Using equation (3), i.e., Roy's identity, in the derivation of the impact of the reform on the social welfare function, we get:

$$
d W=\frac{\partial W}{\partial t_{s}} d t_{s}+\frac{\partial W}{\partial t_{s}} d t_{t}=-\sum_{h=1}^{H} \beta_{h}\left(x_{s}^{h} d t_{s}+x_{t}^{h} d t_{t}\right)
$$

\footnotetext{
${ }^{7}$ If the tax is an ad-valorem tax, then $x$ should be interpreted as expenditure on the commodity.
} 
where $\beta_{h}=\frac{\partial W}{\partial V^{h}} \frac{\partial V^{h}}{\partial y}$ is the social evaluation of the marginal utility of income of individual $h$. The term in brackets is the marginal benefit (or burden) on individual $h$ in monetary terms. Equation (4) is sufficient for analyzing the impact of the reform on the social welfare function. The implications of the reform as regards the government's revenue constraint are discussed in Section 1.3.

Denote by $M B$ the marginal benefit of the reform:

$$
M B_{h}=-\left(x_{s}^{h} d t_{s}+x_{t}^{h} d t_{t}\right)
$$

Note that $d t_{s}<0$ by equation (2), so that the sign of $M B$ is not determined; if $M B>0$, the taxpayer benefits from the reform, and vice versa. Using (5) the effect of the reform on social welfare is:

$$
d W=\sum_{h=1}^{H} \beta_{h} M B_{h}
$$

Equation (6) says that in order to evaluate the reform one needs to know the equivalent of the monetary impact of the reform on each individual, and then to evaluate these monetary impacts by the social evaluation of the marginal utility of income. Equation (6) is the starting point for the distributional analysis, which may take several forms depending on the assumptions imposed on the non-observed "social evaluation of the marginal utility of income". 8

The search for a successful reform is the search for a reform that leads to $d W>0$. There are three major methods of analysis, depending on how much one is ready to assume about our knowledge of $\beta$. In general, the more assumptions are imposed on $\beta$, the less demanding is the analysis of the data.

(1) Pareto Improving Reform: This is the most demanding reform. It requires that $M B_{h} \geq 0$ for all $h$, which means that no one can be harmed by the reform and that one person's gain can not possibly compensate for another person's loss ( Ahmad and Stern, 1984; Dixit,

\footnotetext{
${ }^{8}$ Birdsall and Londono (1987) criticism can be interpreting as suggesting that the social evaluation of the marginal utility of income will also be a function of physical and human assets' holding.
} 
1987). Those kinds of reforms are mainly of a theoretical interest only because it is hard to find them.

(2) Welfare Dominance: Assume that $\beta_{h}>0$ for all $\mathrm{h}$, and that this is the only assumption one is willing to make. This assumption leads us to the literature on Welfare Dominance (Shorrocks, 1983; Slemrod and Yitzhaki, 1991; Mayshar and Yitzhaki , 1995). As far as I know, no one has been able to empirically identify such reforms.

A less demanding assumption is to consider $\beta_{h}>0$ and $\beta_{h y}<0$ for all $\mathrm{h}$ and $\mathrm{y}$, which means that the (social evaluation of) the marginal utility of income is positive, and declining with income. This type of reform has been analyzed in the context of developed countries by Mayshar and Yitzhaki (1995) using British data, and developing countries by Yitzhaki and Lewis (1996) using Indonesian data, and Yitzhaki and Thirsk (1990) with data from the Ivory-Coast. Ahmad and Stern (1984) developed a similar method for evaluating reforms using a specific social welfare function that depends on one parameter that is chosen by the investigator.

One major problem with the above-mentioned techniques is that even if one can come up with all required data, they do not ensure a complete ordering over a given set of reforms. The result is that when two reforms are compared using these methods the answer to the question which reform is preferable may be indeterminate. To overcome this problem, one cannot escape a full characterization of the marginal utility of income, as is done in the next approach, which is the main approach suggested in this paper.

(3) Decomposition: This approach enables one to evaluate a reform by selecting an inequality measure. ${ }^{9}$ To do that, add and subtract in equation (6) the term $\mu_{\beta} \mu_{\mathrm{MB}}$ (i.e., the mean marginal utility of income multiplied by the mean marginal benefit). We can now rewrite (6) as:

$$
d W=\mu_{\beta} \mu_{M B}+\operatorname{cov}(\beta, M B)
$$

\footnotetext{
${ }^{9}$ Ravallion and Datt (1991) perform a decomposition of a change in a poverty index into the impact of growth and redistribution.
} 
Equation (7) decomposes the impact of the reform on social welfare into two components: (i) The net dollar amount added by the reform, $\mu_{M B}$, evaluated by the average social evaluation of the marginal utility of income; it describes whether society benefits, on average, from the tax reform. (ii) The covariance between the marginal utility of income and the marginal benefit from the reform. Note that the social evaluation of the marginal utility of income is a declining function of income, which means that the covariance term is positive (negative, zero) whenever the marginal benefit from the reform is a decreasing (increasing, constant) function of income. Hence, it is the covariance term that reflects the distributional characteristics of the reform, while the first term (the net dollar amount) reflects its impact on economic growth, on average. ${ }^{10}$ To see the implications of (7) consider the following two cases:

1. $\beta$, the marginal utility of income is a given positive constant. In this case the social welfare function is linear and there is no interest in redistribution. The covariance of any pattern of marginal benefits with a constant equals zero, which means that the only relevant characteristic of the reform is its net dollar amount. Hence, whenever distributional issues are ignored the covariance term is set to zero by assumption, so that the only relevant term is the mean benefit. This particular approach of assuming equal $\beta \mathrm{s}$ is the one used in cost-benefit analysis. Needless to say that because it ignores distributional issues it is not used in analyzing tax reforms.

2. In the typical case, where society does care about distribution, the marginal utility of income is positive, and a decreasing function of income. In this case, the sign of the covariance depends on the distributional pattern of the marginal benefit: if it increases (decreases) with income, the sign of the covariance is positive (negative). This means that given the mean benefit, a reform that improves the status of the poor relative to the status of the rich has a greater impact on social welfare.

The above distinction enables us to classify reforms according to two parameters: (i) the net dollar amount added to society and (ii) its distributional pattern. It is worth distinguishing between several types of reforms:

\footnotetext{
${ }^{10}$ Without loss of generality one can set $\mu_{\beta}$ to equal one.
} 
a. A win-win reform has a positive net dollar amount, and a progressive pattern of benefits. In this case, both the mean and the covariance are positive. Note, however, that unlike Pareto-improving reforms, some people — even among the poor — may be harmed by the reform.

b. A trade-off reform involves a trade-off between efficiency and progressivity. This type comes in two variations: (i) a gain in efficiency and a regressive distributional impact (the first term is positive while the second is negative). (ii) An efficiency loss with a progressive pattern (the first term is negative while second is positive). A typical growth-oriented reform may be of the first kind, while a typical poverty-alleviation reform, in which some costs are borne by society (due to redistribution), will involve an efficiency loss and a progressive pattern of redistribution. That is, a typical povertyalleviation reform will involve a negative first term and a positive second term. The answer to whether or not implementation of such reforms is worthwhile depends on the exact specification of the social welfare function that determines whether the sum of the two components is negative or positive.

c. A lose-lose reform. This type of reforms includes all reforms with both an efficiency loss and a regressive pattern of distribution (both terms are negative). Typically, those reforms benefit a small group of individuals who are closely related to the decisionmaking process, while hurting the rest of society. It is this kind of reforms that an evaluation program should try to detect and avoid.

The challenge is to find reforms of the first type and to avoid reforms of the third type.

To evaluate reforms under the decomposition approach one has to impose structure on the social evaluation of the marginal utility of income. Economists are usually reluctant to make such an assumption, a problem sometimes referred to as one of the "choice of distributional weights". This issue is discussed in depth by Devarajan, Squire and Suthiwart-Narueput (1995) (hereafter: DSSP), who point out three major reasons why a major user of Cost-Benefit, the World Bank, no longer uses distributional weights:

Subjectivity. The use of distributional weights requires a judgement about the value of marginal increases in income to different members of society which staff 
which staff are extremely reluctant to make, even though they recognized that the use of equal weights for everybody was itself a value judgement.

Practicality. Many staff held the view that the actual task of identifying who actually benefited from a project was overwhelming.

Efficiency. A more compelling argument took the view that, while government should be clearly concerned about the distribution of income, project selection was not the most efficient instrument for pursuing this goal... [pp. 7-8].

We will mainly deal with the first argument. The second argument actually refers to whether one can gather reliable data on the distribution of benefits from the project, an issue that extends beyond the scope of this paper. The efficiency argument deals with whether one should be concerned with distributional issues in each project. This issue is not relevant in the present case, because we are dealing with first-order approximations, in which case one can add up the marginal benefits from each governmental project to one set of benefits and only then evaluate the impact of the sum of governmental activities. Hence, there is no need for each project to be a progressive one. In addition, the DSSP paper is concerned with physical projects that may have little or no distributional impact. When dealing with a tax reform or a poverty-alleviation program, the issue of income distribution (and hence distributional weights) is unavoidable.

To deal with the subjectivity issue, we argue that although economists feel uncomfortable with selecting distributional weights or social welfare functions, they do use inequality and poverty measures. By choosing an inequality measure the economist implicitly assumes distributional weights. This type of choice of a 'global' system of distributional weights is less demanding than the choice of the weight for each person. Therefore, instead of choosing distributional weights, we will resort to the weighting scheme of several popular measures of inequality. We concentrate mainly on recovering the distributional weighting scheme of the Gini coefficient, because the methodology has already been developed (Yitzhaki, 1994). However, following a similar procedure, one can recover the distributional weights of the coefficient of variation and the Atkinson (1970) index of inequality. 


\subsection{Distrubutional Weights of Inequality Indices}

The right-hand term in equation (7) summarizes the distributional impact of a marginal tax reform in the term $\operatorname{cov}(\beta, M B)$. This term includes two components: the marginal utility of income, and the marginal benefit of the project. The data on the marginal benefit of the project is a basic requirement for any analysis that is concerned with distributional impact. The other component — the social evaluation of the marginal utility of income - cannot be observed directly, and has to be derived from some assumptions. The aim of this section is to argue that anyone who uses an inequality measure or a poverty index is implicitly assuming the pattern of the marginal utility of income. This section will show the distributional weights of several inequality indices such as the Gini coefficient and the coefficient of variation. However, following the same procedure, one can develop the weighting scheme of other inequality measures as well.

To recover the distributional weighting scheme of the Gini coefficient, consider the following social welfare function:

$$
W^{G}=\mu(1-G)
$$

where $\mu$ is mean income and $G$ is the Gini coefficient. This social welfare function evaluates the well-being of a society according to average income and the Gini index of inequality. ${ }^{11}$ Having assumed a specific social welfare function, we can repeat the steps that led us from equation (1) to equation (7). Using the definition of the Gini index as:

$$
\mathrm{G}_{Y}=\frac{2 \operatorname{cov}(\mathrm{Y}, \mathrm{F}(\mathrm{Y}))}{\mu_{Y}}=-\frac{2 \operatorname{cov}(1-\mathrm{F}(\mathrm{Y}), \mathrm{Y})}{\mu_{\mathrm{Y}}},
$$

where $F(Y)$ is the cumulative distribution of income, it can be verified that equation (7) becomes:

$$
d W^{G}=\mu_{M B}+2 \operatorname{cov}((1-F(Y)), M B)
$$

${ }^{11}$ This social welfare function does not represent an additive social welfare function. It does, however, represent Runciman's theory of relative deprivation (Yitzhaki, 1982). 
This implies that when one adopts (8) as the social welfare function, then $\beta=2[1$ $F(Y)$ ], which means that the social evaluation of the marginal utility of income is twice the rank of the person in the income distribution, normalized to be between zero and one. Therefore, the poorest individual in society is assigned a marginal utility of 2 , while the marginal utility assigned to the richest individual is zero (and the average marginal utility is one).

Using the decomposition of the Gini coefficient as in Yitzhaki (1994), we can define the (Gini) income elasticity of the tax reform as:

$$
\eta_{\mathrm{MB}}=\frac{\operatorname{cov}(\mathrm{MB}, \mathrm{F}(\mathrm{Y}))}{\operatorname{cov}(\mathrm{Y}, \mathrm{F}(\mathrm{Y}))} \frac{\mu_{\mathrm{Y}}}{\mu_{\mathrm{MB}}}
$$

Equation (10), and the (Gini) income elasticity enables the characterization of the distributional impact of the tax reform in terms of the impact on the Gini coefficient of real income. The Gini income elasticity is composed of two terms: the ratio of the covariances and the ratio of means. The ratio of covariances can be interpreted as the Ordinary Least Squares regression coefficient of the slope of a regression of marginal benefits on income, using the cumulative distribution as an instrumental variable. As such, it represents the slope of the curve describing the benefits from the reform as a function of income. Since it is based on the slope of a regression curve, the ratio of covariances describes the marginal increase of benefits from the reform along the income distribution, or, alternatively, the marginal propensity to benefit from the reform. The second term on the right is the magnitude of the benefits in terms of average income, or, alternatively, the average propensity to benefit from the reform. The ratio of the two terms is the (Gini) income elasticity. If the elasticity is greater (lower, equal to) than one, the effect of the reform will be to decrease (increase, have no effect on) the Gini of real income distribution. Using equations $\left(7^{\prime}\right)$ and (10) we can sum up the impact of the reform using three parameters:

$$
d W^{G}=\mu_{M B}\left(1+\eta_{M B} G_{Y}\right)
$$


where $G_{Y}$ is the Gini index of inequality in the economy, and $\eta_{M B}$ is the (Gini) income elasticity of the reform. Hence, using the mean income and the Gini index of inequality as the social welfare function enables us to use summary statistics that are derived from those parameters to analyze the effect of the reform: mean benefits from the reform and the Gini income elasticity. Evaluating the reform according to mean benefits implies the use of a linear social welfare function, while using the Gini income elasticity implies using the distributional weighting scheme of the Gini.

Having defined the parameters needed to take into account distributional considerations according to the weighting scheme of the Gini, we can repeat the derivation for other indices of inequality. For example, if we want the distributional impact to be more sensitive than the Gini index to the needs of the poor, one can use the extended Gini coefficient of inequality (Yitzhaki, 1983) and repeat the derivation that led up to equation (11). The new formula for equation (11) will be identical to the equation presented above, except that the (Gini) income elasticity is replaced by the (Extended Gini) income elasticity, and the Gini index is replaced by the extended Gini index. The extended Gini income elasticity will be:

$$
\eta_{M B}(v)=\frac{\operatorname{cov}\left(M B,[1-F(Y)]^{v}\right)}{\operatorname{cov}\left(Y,[1-F(Y)]^{v}\right)} \frac{\mu_{Y}}{\mu_{M B}},
$$

where $v$ is a parameter that is chosen by the investigator. If $v=1$, the extended Gini weighting scheme is identical to that of the Gini index. If $v \rightarrow \infty$, the weighting scheme represents the attitude of the Rawlsian criterion, that is, the max-min criterion. If $v \rightarrow 0$, the weighting scheme represents indifference to inequality. ${ }^{12}$

It should be mentioned that one can follow the same procedure to derive the weighting scheme of other measures of inequality, such as the Atkinson index of inequality (Atkinson, 1970). In this case, the marginal utility of income is $y^{-\varepsilon}$, where $\varepsilon$ is the parameter in Atkinson's index of inequality. However, to the best of my knowledge, the

\footnotetext{
12 The statistical properties of the estimators of the parameters used under the extended Gini weighting scheme have already been investigated, and a computer program to estimate them and their standard errors is available from the author.
} 
statistical properties of the equivalent of the (Gini) income elasticity are not developed. Another interesting measure of inequality is the coefficient of variation. Following the same procedure as above would yield the Ordinary Least Squares regression coefficient of the regression of benefits on income, as the sufficient statistics for the analysis. However, the social welfare function based on the coefficient of variation may violate the criterion of Pareto efficiency. It is also worth mentioning that the weighting scheme of poverty indices is silent as regards the marginal utility of persons above the poverty line. Hence, it is impossible to develop a similar procedure for poverty indices without some modifications. However, one can use the methodology developed in Besley and Kanbur (1988) to find out the distributional weights of poverty measure. The only problem in using poverty indices is that one cannot repeat the steps that led from equation (6) to equation (7). ${ }^{13}$

Our main argument in this section was that it is possible to overcome the need to explicitly specify the exact details of distributional weights by adopting an inequality measure and using the implied weighting scheme. In this case, the analysis of the distributional impact of a reform can be summarized by the effect on two parameters: the mean benefit (i. e., growth) and income elasticity (i.e., distribution). The distributional impact can be estimated using some modification of a regression procedure. Using the effect on mean benefit as the sole criterion means that the social welfare function is assumed to be linear. Hence, in order to find out whether redistribution (poverty alleviation) is costly in terms of growth, one can calculate the impact of the reform twice: first by estimating the impact on mean income, and then by also taking into account the impact on redistribution. A comparison of the two methods of estimation would reveal whether redistribution was costly, and by how much.

For simplicity, the analysis has been restricted to changes in two taxes. From a theoretical point of view, the analysis can easily be extended to include several taxes and a more complex tax function, such as the income tax. In this case one can change the other parameters of the tax function (such as exemptions, allowances and income brackets). The catch is that the more parameters are involved, the more data are required.

${ }^{13}$ Equation (26) in Besley and Kanbur (1988) is the implementation of equation (6) in this paper to a 


\subsection{The Marginal Efficiency Costs of Funds}

The analysis of the distributional impact of a reform is sufficient for an analysis of the impact of tax reforms. Knowledge of who benefits and by how much is the only datum required for the analysis. However, one can glean additional information from the analysis by comparing the overall benefits accruing to the population with the budget constraint of the government, a data source which has not been used before. This additional information enables us to evaluate the change in the marginal deadweight loss caused by the reform and to account for the benefits of the reform. The analysis in this section relies heavily on Slemrod and Yitzhaki (1996).

Our starting point is equation (5), which describes the benefits accruing to individual $h$. The analysis is extended to include changes in several prices. Summation of the benefits over society as a whole yields the aggregate benefit to society. ${ }^{14}$ The aggregate benefit should abide by equation (2), the tax revenue constraint. Hence it is worth comparing the two equations: equation (2) - the revenue constraint and equation (5) - the aggregate benefits to the individuals.

Recall that the benefits accrued by individual $h$ are:

$$
M B_{h}=-\sum_{j=1}^{L} x_{j}^{h} d t_{j} .
$$

The government tax revenue is

$$
R(t, p, y)=\sum_{i} t_{i} X_{i}(p+t, y)
$$

where $X_{i}=\sum_{h} x_{i}^{h}$ is the demand for commodity $i, y$ is a vector of incomes, and consumer prices are $q=p+t$, where $t$ is a vector of specific taxes. Revenue neutrality requires

poverty index.

${ }^{14}$ In this section it is convenient to use aggregate benefits rather than average benefits as in the previous section. Dividing aggregate benefits by the number of people in society yields mean benefits. 


$$
d R=\sum_{i} M R_{i} d t_{i}=0
$$

where $M R_{i}=\partial R / \partial t_{i}$ is the change in overall tax revenue resulting from a small change in the tax rate on commodity $i$. It will be convenient to work with revenue changes expressed in monetary terms rather than with tax parameters, which may differ in their units. Hence the change in tax revenue (denoted by $\delta_{i}$ ) that results from a change in the tax rate on commodity $i, d t$, becomes:

$$
\delta_{i}=M R_{i} d t_{i} .
$$

The marginal tax reform, $d t$, could also be characterized by the vector of tax receipts, $\delta$, and the change in tax revenue would then be: $d R=\sum_{i} \delta_{i}$.

Substituting equations (14) and (13) into (5) and summing the benefits over all individuals yields:

$$
\sum_{h=1}^{H} M B^{h}=-\sum_{i}\left[X_{i} / M R_{i}\right] \delta_{i},
$$

where the left-hand side of (15) represents aggregate benefits ${ }^{15}$ accruing to individuals in society as a result of the reform, while the right-hand side describes the sources of the benefits. Any change in a revenue source, in the revenue constraint of the government, is described by $\delta_{i}$. This amount is evaluated by its cost to society, as reflected in the term $X_{i} / M R_{i}$. This term is the Marginal Efficiency Cost of Public Funds (MECF), which measures the costs to society of increasing (or decreasing) tax revenues by one dollar as a result of using the $i$-th instrument. Therefore, the left-hand of (15) describes benefits to individuals, while the right-hand sets out the sources of these benefits in the government's revenue constraint and the social costs of such changes in revenue sources.

To illustrate the implications of Equation (15) consider a revenue neutral tax reform [where (15) is subject to $\sum_{i} \delta_{i}=0$ ], which involves changes in two taxes only. Then, using

\footnotetext{
${ }^{15}$ Note that benefits can be either negative and positive.
} 
(15), it can be shown that a neutral tax reform that involves only two taxes will reduce deadweight loss in the economy if: ${ }^{16}$

$$
\sum_{h=1}^{H} M B^{h}=-\left\{\left(\frac{X_{1}}{M R_{1}} \delta_{1}\right)-\left(\frac{X_{2}}{M R_{2}} \delta_{1}\right)\right\}=\left\{M E C F_{2}-M E C F_{1}\right\} \delta_{1}>0 .
$$

This means that only if $M E C F_{2} \neq M E C F_{1}$ will it be possible to find a deadweightreducing tax reform. If $M E C F_{1}>(<) M E C F_{2}$, one can choose $\delta_{1}>(<) 0$ for the reform to have an efficiency gain.

The MECF is an indirect way of estimating the marginal excess burden of each source of tax revenue or subsidy. To evaluate the marginal excess burden one has to evaluate two counterfactual estimates of changes in tax revenue. Consider a small change in the tax rate. Then one has to evaluate two counterfactual possible changes in tax revenue: (i) the change in tax revenue in the absence of a behavioral response by taxpayers $\left[X_{i}\right.$ in equation (16), which is the tax base]; (ii) the change in tax revenue assuming that taxpayers do respond $\left[M R_{i}\right.$ in equation (16)]. The ratio of the two minus one (the tax collected) is the marginal excess burden. The intuitive explanation of this result is the assumption that, on the margin, a taxpayer will spend up to a dollar to save a dollar of taxes.

To sum up: to estimate the MECFs requires a tax calculator which can evaluate two parameters for each tax instrument:

(a) The marginal change in revenue, $M R_{i}$.

(b) The tax base, $X_{i}$, which is the expected change in tax revenue if no other change occurs.

In many practical estimations $X_{i}$ is also used as an estimate of $M R_{i}$, in which case the interpretation is that all MECFs are assumed to be equal to one. This is equivalent to assuming Lump-sum taxation.

Using the MECF concept enables assessing the consistency of the assumptions concerning the aggregate benefits of a reform given the government's revenue constraint. The benefits should be consistent with the assumptions concerning the change in the

\footnotetext{
${ }^{16}$ Since aggregate benefits are positive, it must be true that the deadweight loss is reduced.
} 
revenue constraints of the government and the changes in the deadweight loss in the economy.

\section{PROJECT EVALUATION}

This section argues that the methods presented in Section 1, with minor adaptations, can form the base for analyzing the impact of projects on growth and redistribution in society. The methods are applicable both to physical and nonphysical projects. Provided that the relevant data exist, they can handle the analysis of the supply of public goods and the impact of projects that affect poverty or the environement. The only restriction is that the project must be marginal — that is, first-order approximation rules must yield good approximations of the evaluation.

To adapt the methodology to project evaluation requires taking into account two major differences between the kind of tax reforms discussed above and projects. The first point is that a project takes more than one period to be completed (the impact of a tax reform may be immediate, whereas projects take time to mature); the second is that whereas in the case of tax reforms the benefits to individuals are in terms of price changes, projects affect quantities supplied as well.

The first difference is more serious than the second, because in a one-period model individuals are assumed to live throughout the reform. In a multi-period model it is not at all clear that all individuals will outlive the project; some individuals will join society or exit from it as a result of the project. Since the proposed methods do not take such demographic responses into account, they may fail to correctly evaluate the project distributional impact. To avoid these complications it is assumed that all members of society live for two periods. This restriction means that the suggested methodology is not suitable for projects that affect demographic development - any policy that impinges on fertility, mortality, or life-expectation cannot be handled by the suggested methodology. To give an extreme example: failure to care for the poor will reduce the number of the poor. Therefore, it is important to stress that the methodology presented in this paper is not capable of handling projects that are intended to change demographic development. 
Sen (1998) has stressed the importance of mortality as an indicator of economic welfare. To adjust the methodology to account for demographic changes one can follow one of the following approaches: (a) add another target to evaluate projects. That is, in addition to the social welfare function one should add demographic targets to the analysis. (b) assign an appropriate price to the value of human life - i.e., a weight should be attached to mortality, fertility, and unborn children. Handling those issues comes with a price tag - a more complicated methodology, hence those issues are beyond the scope of this paper. Bearing this caveat in mind, the extension of the model to evaluate projects is straightforward. All one has to do is to increase the number of periods to at least two.

The other major difference between the analysis of a tax reform and a project is that whereas a tax reform affects prices only, a project may affect quantities. For example, if a project increases, say, a community's water supply, one has to evaluate each added unit of water by the willingness to pay for it. To illustrate the kind of modifications needed it is assumed that as a result of the project a change occurs in the quantity of one commodity, combined with changes in the prices of several other commodities.

The extended model includes two periods and a public good. The marginal benefits accruing to individual $h$ is:

$$
M B_{h t}=-\sum_{j=1}^{J} x_{j t}^{h} d t_{j t}+\omega_{h t} d G_{t},
$$

where the additional index $t=1,2$ denotes first or second period, respectively; $d G_{t}$ is the change in the quantity of a public good in period $t$; and $\omega_{h t}$ is the willingness to pay for the public good by individual $h$ in period $t$. The basic idea of relying on the marginal change for evaluating the project does not dramatically change the formal treatment of the problem. However, one should not discard the additional complication added by the need to estimate the willingness to pay and the change in the amount of the public good.

The reliance on the willingness to pay brings to the fore the inappropriateness of CostBenefit analysis for dealing with distributional issues. Consider the following example taken from Copp (1987), who reformulated it based on Schrader-Frechette (1980). "If Rachel and Paula are equally afflicted with asthma, then the clean air project might be of 
equal medical benefit to them, and this fact could be expressed in terms of increased breathing efficiency they can expect if the project is implemented. Yet if Rachel is rich while Paula is poor, she may be willing to pay more than Paula for this benefit, because she is able to pay more, and because money has a greater opportunity cost for Paula than for Rachel. ... Because $\mathrm{CB}$ analysis measures the magnitude of costs and benefits on the basis of willingness to pay, it gives greater weight to the gaining and losing of resources by the wealthy than to the gaining and losing of resources by the poor." (Copp, 1987, p-75, italic at source).

The reason for this irritating example is that although $\mathrm{dG}$ in equation (5') is equal for Paula and Rachel, the willingness to pay, other things being equal, is an increasing function of income. Cost Benefit analysis which is intended to imitate the way a market would have functioned, assigns equal weight to each dollar and not, as one may expect, equal weight to each person. Therefore, it should not be surprising that distributional justice contradicts Cost-Benefit Analysis. This seemingly unfairness in cost benefit analysis leads Copp to write "The objection is that $\mathrm{CB}$ analysis is unfair in the way it measures the impact of proposed social projects and policies on individuals, for it does not take people's interest into account in an even handed way." (Copp, 1987, p-76). To overcome this objection one needs to have a social welfare function, so that the declining social evaluation of the marginal utility of income with income overcomes the increase in the willingness to pay as a result of the increase in income.

The social welfare function is defined over two periods as:

$$
W_{p}=W\left[V_{1}^{1}(), \ldots, V_{1}^{H}()\right]+\gamma W\left[V_{2}^{1}(), \ldots, V_{2}^{H}()\right]
$$

where $\gamma$ is the social discounting rate, and $W_{p}$ is the "present value" of the periodical social welfare functions, discounted by the social discount rate. ${ }^{17}$

${ }^{17}$ An alternative formulation of the social welfare function is to define it on individuals' utility, where each individual lives two periods. This alternative formulation is harder to handle because one has also to handle correlation in individuals' incomes over time. Equation (17) describes a government which relies on the typical (yearly) income tax law to redistribute income. 
The rest of the analysis follows similar changes. Equation (7), which describes the distributional impact of the project, becomes:

$$
\begin{aligned}
d w_{p}= & \mu_{\beta 1} \mu_{M B 1}+\gamma \mu_{\beta 2} \mu_{M B 2} \\
& +\operatorname{cov}\left(\beta_{1}, M B_{1}\right)+\gamma \operatorname{cov}\left(\beta_{2}, M B_{2}\right),
\end{aligned}
$$

which can be interpreted in the following way: instead of looking at the mean marginal benefit from the project, one looks at the present value of the discounted marginal benefit (discounted by the social discount rate). Adding up the impacts of the project on mean incomes in the first and second periods (first and second term in ( $\left.7^{\prime}\right)$ ) reflect the impact of the project on growth, ignoring distributional issues. In practice, such calculations are similar to calculating the rate of return to the project, ignoring distributional considerations. The third and forth terms reflect the distributional impact of the project, discounted by the social discount rate. If we are dealing with an investment project, the first period would reflect the distributional impact of financing the project while the second period reflects the distributional impact of the project's benefits.

It is a straightforward extension of the above modification to repeat the development pointed out in Section 1 (equations (6) to (10) in order to demonstrate how inequality measures can be used as substitutes for the social welfare function. For example, by using the Gini index of inequality to represent inequality in each period, one has to find out the periodical Gini income elasticities to evaluate the distributional impact of the project in each period. One can then find the present value in the two-period as a weighted sum of the periodical Gini income elasticities.

A similar pattern of extension can be applied to the concept of MECF. In a two- period model, calculate the MECF in each period and then calculate the present value of the MECF for different projects for different periods. However, there is no point in trying to formalize these arguments because of the enormous data collection problems entailed in their implementation. 
We have shown that at least at the formal level the theory of tax reform can easily be extended to handle cost-benefit analysis. ${ }^{18}$ The advantage of this observation is that it enables the application of cost-benefit analysis to non-physical projects that result in redistribution. In practice, the implications of using the theory of tax reform in cost-benefit analysis is that one can analyze the growth component of a project and its distributional implications separately. The growth component can be estimated, as before, by using regular methods of cost-benefit analysis (that is, the rate of return of the project). The distributional impact can be evaluated by choosing an inequality index and using its implied distributional weights. The evaluation of the distributional implications can utilize existing inequality measures so as to achieve the following objectives: (a) The subjectivity of selection of distributional weights is reduced, because by selecting an inequality measure the whole set of distributional weights is selected. (b) By using inequality measures one can summarize the distributional impact by one parameter - the income elasticity based on the use of that inequality measure. If the social welfare function includes both mean income and inequality as parameters, the substitution between the two targets can be detected. In addition, in the case of public funds being involved, it is recommended that whenever possible one should calculate the MECF - the efficiency cost of public funds - to evaluate the additional excess burden caused by the project.

An alternative way of implementing the evaluation method suggested in this paper is to first calculate the rate of return to the project, ignoring the distributional implications. This is equivalent to calculating the rate of return based on the first two components of equation $\left(7^{\prime}\right)$. Denote this efficiency rate of return by $r_{e}$. Now calculate the rate of return using distributional weights. This is equivalent to calculating the rate of return relying on all the components of $\left(7^{\prime}\right)$. Denote the resultant rate of return by $r_{d}$ - the distribution-weighted rate of return. Now, as before, one can differentiate between three typical cases:

a. Gain-gain Projects $\left(\gamma<r_{e}<r_{d}\right)$ : The efficiency rate of return and the distributional rate of return are greater than the social discount rate. Also, the distributional rate of return

\footnotetext{
${ }^{18}$ And vice versa: cost-benefit analysis can be extended to handle tax reforms.
} 
is greater than the efficiency rate of return. In this case, the project both causes growth in the economy and the growth is biased toward the poor.

b. Trade-off Projects. A trade-off project is a project in which one objective must be sacrificed in order to gain another target. One can distinguish between two types such projects: (i) Distributional projects, where $r_{e}<\gamma<r_{d}$. In this type of projects society forgoes resources in order to improve the status of the poor. (ii) Growth Projects, where $r_{d}<\gamma<r_{e}$ or $\gamma<r_{d}<r_{e}$. In the first case, growth is achieved while inequality increases. The former would not have been approved because redistribution is worse than without the project. While this type of growth has a deleterious effect on the poor in the short run, it may benefit the poor in the long run because of the growth it induces.

c. Loss-Loss Projects. if $r_{d}<\gamma$ and $r_{e}<\gamma$, then the project does not promote either growth or redistribution. Such cases may be the result of miscalculations; they can also be deliberately designed to benefit a small group of rent-seekers. The aim of an evaluation program is to identify such projects.

In this section we have shown that one can, with a few modifications, adjust the theory of tax reform to address almost the same issues as cost-benefit analysis. The implementation enables the unification of analytical tools and can incorporate cost-benefit analysis as a special case.

To be fair, it should be mentioned that one might argue, using almost the same arguments, that cost-benefit analysis can incorporate, with a few modifications, the theory of tax reform.

The implications of the methodology are as follows: to evaluate whether distributional considerations should have a role in a project one has to evaluate two kinds of project's rate of return. One rate of return is the distributional rate of return, where each dollar of outlays or benefits is evaluated according to the social evaluation of the marginal utility of income of the affected person. The second rate of return, the efficiency rate of return, where each dollar is assigned an equal value. Comparison of the resulting rates of return enables us to calculate the price, in terms of forgone output, of achieving redistribution. 


\section{FINAL REMARKS}

The method suggested in this paper is based on adopting the framework of the theory of tax reform as the basic tool for the analysis. I believe that this framework is adequate for supplying a framework for handling the evaluation of whether a given policy has an impact on poverty alleviation. There are several advantages to such an approach:

a. It breaks down the impact of a project (or a set of projects) into a growth component and a redistribution component.

b. It utilizes an (almost) existing framework and will therefore be easy to implement.

c. It can be extended easily to handle externalities, such as the environment. Eskeland and Kong (1998) offers a framework that can be easily adjusted to the framework suggested in this paper.

The main drawback of the proposed method is that it is more demanding than other methods in terms of data requirements. But this seems to be the price one has to pay to deal with distributional issues. 


\section{References}

Ahmad, E. and N. Stern (1984). "The Theory of Reform and Indian Indirect Taxes," Journal of Public Economics, 25: 259-298.

Atkinson, A. B. (1970). “On the Measurement of Inequality,” Journal of Economic Theory, 2: 244263.

Birdsall, Nancy and Londono, Juan Luis (1997). "Asset Inequality Matters: An Assessment of the World Bank Approach to Poverty Reduction," American Economic Review, 87, 2, (May), $31-37$.

Besley, Timothy and Ravi Kanbur (1988), "Food Subsidies and Poverty Alleviation," The Economic Journal, 98, (September), 701-719.

Copp, David (1987), "The Justice and Rationale of Cost-Benefit Analysis," Theory and Decision, 23, (July), 65-87.

Devarajan, S., L. Squire and S. Suthiwart-Narueput . (1995). "Reviving Project Appraisal at the World Bank," PRD Research Paper No. 1496. The World Bank.

Dixit, Avinash (1987), "On Pareto-Improving Redistributions of Aggregate Economic Gains," Journal of Economic Theory, 41, 133-153.

Dreze, Jean and Nicholas Stern (1987). The Theory of Cost-Benefit Analysis", In Handbook of Public Economics, 2, edited by Alan J. Auesrbach and Martin Feldstein , 909-89. Amsterdam: North Holland.

Eskeland, Gunnar S. and Chingying Kong (1998). "Protecting the Environment and the Poor: A Public Good Framework, and an Application to Indonesia, Development Research Group, The World Bank, (April), Mimeo.

Glenn, Jenkins P. (1997). "Project Analysis and the World Bank," American Economic Review, 87, 2, (May), $38-48$.

Harberger, Arnold C. (1978). “On the Use of Distributional Weights in Social Cost-Benefit Analysis," American Economic Review, 87, 2, (May), 38- 48.

Kleiman, Ephraim (1972). “The Frustration and Enhancement of Income Redistribution,” Kyklos, 25(2), 288-304.

Little, I. M. D. and James A. Mirrlees (1974). Project Appraisal and Planning for the Developing Countries. London: Heinemann Educational Books.

Mayshar, Joram and Shlomo Yitzhaki (1995). "Dalton-Improving Indirect Tax Reforms," American Economic Review, 85 (No. 4, September): 793-808. 
Pearce, D. W. and Nash, C. A. (1981). The Social Appraisal of Projects: A Text in Cost-Benefit Analysis, London: MacMillan Press Ltd.

Ravallion, Martin and Gaurav Datt (1991). "Growth and Redistribution Components of Changes in Poverty Measures: A Decomposition with Application to Brazil and India in the 1980s," Living Standards Measurement Study, WP No. 83, The World Bank.

Ravallion, Martin and Gaurav Datt (1995). "Is Targeting Through a Work Requirement Efficient?," in Dominique van de Walle and Kimberly Nead (eds.,) Public Spending and The Poor: Theory and Evidence, Baltimore, MD: John Hopkins University Press.

Schrader-Frechette, Kirstin S. (1980). "Technology Assessment as Applied Philosophy of Science," Science, Technology and Human Values, Special Issue, 33, (Fall), 36-37.

Sen, Amartia (1998), "Mortality as an Indicator of Economic Success or Failure," The Economic Journal, 108, 447, (January), 1-25.

Shorrocks, Anthony F. (1983), "Ranking Income Distributions," Economica, 50, 197, (February), 317.

Squire, Lyn (1980), "On the Use of Distributional Weights in Social Cost-Benefit Analysis," The Journal of Political Economy, 88,5, 1048-9.

Squire, Lyn (1995), "Evaluating the effectiveness of poverty alleviation programs," ch 5, in Proceedings of The World Bank Conference on Evaluation and Development, Whashington D. C.

Squire, Lyn and Herman G. van der Tak (1975). Economic Analysis of Projects, Baltimore, MD: John Hopkins University Press.

Usher, Dan (1998). "Efficiency as a Criterion for The Legislature and The Courts," Dept. of Economics, Queen's University, mimeo.

Yitzhaki, Shlomo and Joel Slemrod (1991). "Welfare Dominance: An Application to Commodity Taxation”, American Economic Review, 81, No. 3, June 1991, 480-496.

— and - (1996). "The Social Cost of Taxation and the Marginal Cost of Funds," International Monetary Fund Staff Papers, 43 (No. 1, March): 172-198.

Yitzhaki, Shlomo (1982). "Relative Deprivation and Economic Welfare," European Economic Review, 17, (January), 99-113.

Yitzhaki, Shlomo (1983). "On an Extension of Gini Inequality Index," International Economic Review, 24, No.3, (October), 617-28. 
Yitzhaki, Shlomo (1994). “On the Progressivity of Commodity Taxation.” In Wolfgang Eichhorn (ed.), Models and Measurement of Welfare and Inequality. Heidelberg: Springer-Verlag, pp. $448-465$.

— — and Jeffrey Lewis (1996). "Guidelines on Searching for Dalton-Improving Tax Reforms: Illustrations with Data from Indonesia," The World Bank Economic Review, 10 (No. 3): 54162.

— and Wayne Thirsk (1990). "Welfare Dominance and the Design of Excise Taxation in the Cote D'ivoire ," Journal of Development Economics, 33 (No. 1): 1-18. 